\section{Thalamic Pain Syndrome}

Jennifer Sue Kleiner

Department of Psychology, University of

Arkansas for Medical Sciences Blandford

Physician Center, Little Rock, AR, USA

\section{Synonyms}

Dejerine-Roussy syndrome

\section{Current Knowledge}

First defined in 1906, thalamic pain syndrome may occur in individuals with lesions affecting the thalamus, most commonly stroke. Also known as Déjerine-Roussy syndrome, the pain may begin soon after the stroke or may only gradually evolve after weeks to months following the episode, although not all thalamic strokes result in this syndrome. When it occurs, the pain may be associated with or follow weakness and/or a general loss of sensation on the side of body contralateral to the stroke. Thalamic pain appears to be the result of altered perception of or hypersensitivity to most or all forms of tactile or cutaneous stimulation, including light touch and changes in temperature. These symptoms can be made worse during periods of emotional distress. The quality of the pain sensation varies, being described as burning, tearing, or shooting, but nearly always as very distressing, often lasting well beyond the stimulus that evoked it.

\section{Cross-References}

Thalamus

\section{References and Readings}

Pearce, J. M. S. (1988). The thalamic syndrome of Dejerine and Roussy. Journal of Neurology, Neurosurgery, and Psychiatry, 51, 676.

Schott, G. D. (1995). From thalamic syndrome to central poststroke pain. Journal of Neurology, Neurosurgery, and Psychiatry, 61, 560-564. 